Available online at http://iddtonline.info

RESEARCH ARTICLE

\title{
COMPARATIVE STUDY OF QUININE PLUS DOXYCYCLINE VERSUS ARTEMETHER PLUS DOXYCYCLINE IN UNCOMPLICATED PLASMODIUM FALCIPARUM MALARIA IN A TERTIARY CARE TEACHING HOSPITAL OF EASTERN INDIA
}

\author{
*Bandyopadhyay Debasis ${ }^{1}$, Singha Prasanta ${ }^{2}$ \\ ${ }^{1}$ Associate Professor, Department Of Pharmacology, Burdwan Medical College \&Hospital, West Bengal, India-713104 \\ ${ }^{2}$ Medical Officer, Burdwan Medical College \&Hospital, West Bengal, India-713104 \\ Email ID* of the Corresponding Author: drdebasisbandyopadhyay@yahoo.in, Mobile No. 09474786492
}

\begin{abstract}
Background: The treatment of falciparum malaria has changed over the past two decades in response to declining sensitivity of P. falciparum to conventional antimalarial drugs. The treatment depends on patient's age, the severity of infection, the likely pattern of susceptibility to antimalarial drugs, cost and availability of such drugs. For this reason recommendations vary according to geographic region and should be under constant review. In this perspective we conducted the present study in this part of the world, Burdwan Medical College, West Bengal, India, where no such study conducted before. Objective: The objective of our study was to evaluate the efficacy of Artemether and Doxycycline combination against Quinine and Doxycycline combination in acute uncomplicated falciparum malaria as the primary objective. Our secondary objective was to evaluate the safety profile of the two combination regimens in terms of the adverse event profiles. Materials and Methods: In this study total 84 patients were randomly recruited after fulfillment of the inclusion criteria, from the Medicine inpatients Department of Burdwan Medical College\& Hospital, West Bengal, during the period of May 2007 to December 2010. All the eligible patients suffering from uncomplicated falciparum malaria were randomly allocated to two groups. The $1^{\text {st }}$ group was receiving Quinine sulfate $10 \mathrm{mg}$ salt per kg body weight 8 hourly for 7 days plus Doxycycline hyclate $100 \mathrm{mg} 12$ hourly for 7 days. And the $2^{\text {nd }}$ group was receiving Artemether $80 \mathrm{mg}$ every 24 hours for 5 days with an additional $80 \mathrm{mg}$ dose 12 hours after the first dose, plus Doxycycline hyclate $100 \mathrm{mg}$ ( of Doxycycline) 12 hourly for 7 days. They were discharged after 7 days and advised for follow up on days 14 and 28. Efficacy was measured by the two variables: [1] Primary efficacy variables, included as (i) Fever Clearance Time and (ii) Parasite Clearance Time and the [2] Secondary efficacy variables, included as (i) Cure Rate and (ii) Relapse Rate. Results: In our study, cure rate was $84.21 \%$ and $100 \%$ of the $1^{\text {st }}$ group \& $2^{\text {nd }}$ group respectively, with the later was significantly better than the $1^{\text {st }}$ one $(p=0.014)$. Fever Clearance time of the $2^{\text {nd }}$ group was significantly shorter $(\mathrm{p}=0.001)$ than that of the $1^{\text {st }}$ one and the Parasite Clearance Time of the $2^{\text {nd }}$ group was also significantly shorter $(\mathrm{p}=0.002)$ than that of the $1^{\text {st }}$ one. Though the frequency of nausea and vomiting was slightly higher in the $2^{\text {nd }}$ group, but not statistically significant $(\mathrm{p}=0.11)$. Conclusion: In our study, in this institution combination of Artemether plus Doxycycline was highly effective than the combination of Quinine plus Doxycycline in the uncomplicated falciparum malaria and was well tolerated.
\end{abstract}

Key Words: Malaria, Plasmodium falciparum, Uncomplicated, Artemether, Doxycycline

\section{INTRODUCTION}

Malaria is the world's most important parasitic infection ${ }^{1}$. At present about 100 countries or territories in the world are considered malarious, almost half of which are in Africa, south of the Sahara ${ }^{2}$. The incidence of malaria worldwide is estimated to the 300-500 million clinical cases each year- majority caused by Plasmodium falciparum. Malaria is thought to kill between $1.1 \& 2.7$ million people worldwide each year ${ }^{2}$ and kills a child somewhere in the world every 30 seconds ${ }^{3}$.

The treatment of Plasmodium falciparum malaria has been changed over the past two decades in response to declining sensitivity of Plasmodium falciparum to conventional antimalarial drugs ${ }^{1}$. The parasite remains fully sensitive to chloroquine only in Central America, north of the Panama Canal, in Haiti, Egypt and in scattered pockets of Asia and South America ${ }^{4}$. Southeast Asia, including India, lie in the zone of chloroquine resistance ${ }^{2,4}$. However, world maps that depict countries as having or not having drug resistant malaria are potentially misleading, as there is great heterogeneity within countries and across boundaries. Local knowledge is therefore of paramount importance ${ }^{4}$.

The treatment of malaria depends on patient's age, the severity of infection, the likely pattern of susceptibility to antimalarial drugs, cost and availability of such drugs. For this reason recommendations vary according to geographic region and should be under constant review ${ }^{1}$. Though chloroquine is still the mainstay of antimalarial treatment, the emergence of Plasmodium falciparum resistant to this drug has challenged control efforts and has been linked to increased mortality ${ }^{5}$. Krishna ${ }^{6}$, stated that "assume that Plasmodium falciparum is chloroquine resistant unless in an area with known chloroquine sensitivity". White and Breman 7, have opined "in areas where Plasmodium falciparum is still sensitive, chloroquine is used as the second drug". Todd et al. ${ }^{8}$, also agreed with this view and recommended that "Plasmodium falciparum is now resistant to chloroquine almost worldwide, notable in Asia and Africa, so quinine is the drug of choice as dihydrochloride or sulfate".

Quinine is a good alternative to chloroquine but it has several limitations ${ }^{9}$. It is used in combination with tetracyclines, such as doxycycline, in areas where quine resistance is also documented or possible. The artemisinin derivatives are better tolerated alternatives to quinine. Artemisinin and its derivatives are sesquiterpene lactone peroxides derived from the leaves the sweet wormwood (Artemisia annua) and related plants ${ }^{4}$. It has been used 
traditionally in Chinese medicine as 'qinghaosu'pronounced 'ching-how-soo' 10. Three derivatives are currently available- Artesunate, a water soluble form, and the lipid soluble Artemether and Arteether ${ }^{11}$. Artemisinin derivatives kill all stages of malaria parasites, including 'young rings' by interacting with heme to produce carboncentered free radicals that alkylate proteins and membranes 11. They have potent antimalarial activity, attractive safety profiles and are yet to be associated with significant resistance ${ }^{5}$. Qinghaosu and its derivatives have been studied extensively in China and Southeast Asia during the last 10 years. The effectiveness of these drugs in clearing parasites has been thoroughly documented ${ }^{12}$.

The essence of our study is to search for a better combination regimen in comparison to the older quininedoxycycline duo. There is growing belief among malariologists that to prevent resistance, falciparum malaria should no longer be treated with single drugs in endemic areas, the same strategy that has been applied to the treatment of other infectious diseases of major global public health significance such as tuberculosis and HIV/AIDS. This strategy is based upon simultaneous use of two or more drugs with different modes of action ${ }^{7}$. The basic tenet is that the probability of resistance developing simultaneously to two chemotherapeutic agents with independent mechanism of action is extremely low, of the order of once in $10^{12}$ treatments. This frequency is the product of the probabilities of the acquisition of a resistant mutation to each drug multiplied by the number of parasites in a typical infection ${ }^{3}$. Combinations also prevent recrudescence or relapse of symptoms.

Combination of quinine with doxycycline is time-tested and retains at least $85 \%$ effectiveness nearly everywhere ${ }^{1}$. As quinine has limitations and artemisinin compounds are good alternatives, several drug combinations with artemisinin have been and are being evaluated till date. For example, artesunate plus amodiaquine, artemisinin derivative with mefloquine, artemether with lumefantrine and so on. Assessment of these and other effective and well-tolerated combination regimens containing artemisinin compounds is needed in other geographical areas ${ }^{5}$. In this scenario we conducted our study in this geographical area, Burdwan Medical College\& Hospital, West Bengal, India. For our study we had chosen artemether in combination with doxycycline and compared to the standard quinine plus doxycycline regimens. All drugs were administered by the oral route.

\section{MATERIALS AND METHODS}

Study duration: For the individual patients, the study duration was 28 days including follow-up study visits. The entire study was completed from May 2007 to December 2010 .

Ethical consideration: This study was conducted in accordance with the principles enunciated in the Declaration of Helsinki for Biomedical Research involving Human Subjects. Also every effort was made to adhere to the spirit of the Good Clinical Practice guidelines of the Government of India ${ }^{13}$. Written informed consent was taken from each of the individuals. The protocol and the patients' informed consent form was approved by the Institutional Ethics Committee.
Sample size: Total 84 patients, suffering from uncomplicated falciparum malaria, were recruited from the Medicine inpatients Department of Burdwan Medical College,West Bengal, after fulfillment of the inclusion\& exclusion criteria.

\section{Inclusion criteria:}

a) Subject aged between 15 to 65 years.

b) Subject weighing at least $45 \mathrm{~kg}$.

c) History of fever $\left(\geq 100{ }^{0} \mathrm{~F}\right)$ within the past 48 hours.

d) Screening of peripheral blood smears showing presence of Plasmodium falciparum.

e) Willing to provide written informed consent.

\section{Exclusion criteria:}

a) Female subject who is pregnant or breast feeding.

b) Estimated extent of parasitaemia $>10^{5} / \mu \mathrm{L}$.

c) Screening of peripheral blood smears showing presence of mixed malarial infection i.e. Plasmodium vivax + Plasmodium falciparum.

d) Subject having evidence of

- Impaired consciousness.

- $\quad$ Severe anemia $(\mathrm{Hb}<5 \mathrm{~g} / \mathrm{dL})$.

- Jaundice or compromised liver function (ALT or AST > 3 times upper limit of normal.

- Respiratory distress.

- Hamaturia.

- Hypoglycemia (Blood glucose $<70 \mathrm{mg} / \mathrm{dL}$ ).

e) Subject having history of

- Optic neuritis.

- Significant tinnitus.

- Severe glucose-6-phosphate dehydrogenase (G6PD) deficiency.

- $\quad$ Severe cardiac dysrhythmias.

f) History of use of any antimalarial for the current febrile episode or within the past 1 month.

g) History of use of any medication that may influence the activity of antimalarial drugs, e.g. folate, azithromycin, dapsone, etc. , within the past 7 days or longer depending upon the nature of the drug.

h) History of Blood transfusion within the past 1 month.

i) History of allergy (hypersensitivity) to artemether, quinine, doxycycline or closely related drugs.

j) Any concomitant serious disorder of the kidney, heart, lungs or other vital organs.

k) Unwilling to remain hospitalized for at least 7 days or to return for follow up at the stipulated days on $14^{\text {th }}$ day and $28^{\text {th }}$ days.

l) History of alcohol or substance abuse.

\section{Study Methodology:}

a) Study design: Our study was post registration (Phase IV), prospective, open, randomized, controlled study with the two parallel treatment groups.

b) Study time schedule: All the recruited subjects were admitted to the medicine inpatients departments and was studied as in-patient for 7 days. Thereafter they were discharged \& was advised to come on the day 14 and $28^{\text {th }}$ days for follow up study. 
c) Baseline assessment: At presentation every patient was screened for presence of a history of fever within the past 48 hours and the presence of Plasmodium falciparum in the peripheral blood smear. A serological test for Plasmodium falciparum HRP-2 antigen was also carried out. Blood was also collected for baseline laboratory test including complete hemogram \& blood biochemistry.

d) Study evaluation: Plasmodium falciparum infection was diagnosed first. Then the response to study drugs was evaluated by Primary \& secondary efficacy variables. Diagnosis of falciparum malaria was based on blood smear test 5,12 and detection of Plasmodium falciparum HRP-2 antigen with a rapid dipstick antigen capture assay ${ }^{14}$.

Blood Smear Test: Both thick \& thin films were prepared from finger prick blood samples and stained with $2 \%$ Giemsa stain for 30 minutes. All smears being examined at the magnification of 1000. Blood smear was collected every 12 hours interval after commencement of treatment until two consecutive examinations were negative. From blood smear quantization of the parasitemia was done as follows. Total RBC or WBC was counted first. Then the number of asexual parasites per $1000 \mathrm{RBC}$ in a thin film or parasites per $200 \mathrm{WBC}$ in a thick film counted. Parasite density was calculated by multiplying both the numbers and expressed as parasites per $\mu \mathrm{L}$. Blood film considered as negative when no parasites were seen in 200 oilimmersion fields in a thick blood film ${ }^{5,12}$.

Detection of Plasmodium falciparum HRP-2 antigen by rapid dipstick antigen capture assay: Antibody capture of circulating plasmodium specific antigens -a technique proposed for rapid diagnosis of malaria ${ }^{14}$. The Plasmodium falciparum histidine rich protein-2 (PfHRP2)- a water soluble antigen released by blood stages of the parasite- a target for antigen capture assay. Fifty $\mu \mathrm{L}$ blood placed in a labeled polypropylene tube and three drops (about $100 \mu \mathrm{L}$ ) of a RBC lysing agent added. After gently agitating the tubes, specimens were ready for testing by the antigen capture assay. Assay test sticks were made of cellulose fiber and contain an immobilized $\operatorname{IgG}_{1}$ monoclonal antibody directed against the synthetic peptide (AHH [AHHAAD] ${ }_{2}$ ) from PfHRP2. Test sticks were packaged with desiccant in foil pouches and kept unrefrigerated. One drop of a lysed blood specimen dispensed into one well of a ten-specimen test-stick holder platform. The end of a test-stick was placed in the drop of lysed blood. The drop of blood was absorbed by the teststick along its entire length, a process required 2- 10 minutes depending on the specimen.PfHRP2 antigen detector reagent (containing polyclonal antibodies against PfHRP2 that conjugated to liposomes containing pink dye) was then added to every specimen well. After the antigen detector reagent was absorbed by the test-stick, a wash reagent was added and absorbed. The result was read immediately. A positive test result (PfHRP2) showed as a thin, solid, pink band that appeared on the dipstick.

Different field studies showed that when Plasmodium falciparum asexual parasitemia is greater than 60 parasites per $\mu \mathrm{L}$, the dipstick test is $96.5-100 \%$ sensitive ${ }^{2}$. At lower level of parasitemia the sensitivity decreases; however at 11-60 parasites per $\mu \mathrm{L}$ of blood, the assay still detects 70 -
$80 \%$ of infection and at 10 parasites per $\mu \mathrm{L}$ of blood or less, the assay detects $11-67 \%$ of infection ${ }^{13}$. Since most individuals with symptomatic Plasmodium falciparum infection have greater than 60 parasites per $\mu \mathrm{L}$ of blood, the dipstick assay will be of particular use in rapid diagnosis of febrile patients and in epidemiologic field studies ${ }^{12}$. Furthermore because inexperienced microscopists often have difficulty in detecting less than 60 parasites per $\mu \mathrm{L}$ of blood, assessment of comparative sensitivity of blood films and dipstick assay among such technicians may indicate that dipstick has greater sensitivity than blood smear. Further the test is easy to perform, does not require electricity or elaborate equipment. Only a small amount of unprocessed whole blood is required. Analysis of a single specimen can be completed within 20 minutes. Usually PfHRP2 antigen is not detectable in blood 6 days after initiation of current chemotherapy suggesting that circulating antigen rarely lead to false positive test ${ }^{14}$. However, one problem with PfHRP-2 based tests is the persistence of HRP-2 antigen after effective treatment, possibly making these tests less suitable for identifying treatment failure ${ }^{2}$. Hence this test was not used during follow up period in this study.

Study treatment: All the eligible subjects were randomly allocated in to two treatment groups. [A] $1^{\text {st }}$ group total patients were 43 . They received Quinine sulfate $10 \mathrm{mg}$ ( of the salt ) per kg body weight 8 hourly for 7 days plus Doxycycline hyclate $100 \mathrm{mg}$ ( of doxycycline ) 12 hourly for 7 days.

[B] In the $2^{\text {nd }}$ group total patients were 41. They received Artemether $80 \mathrm{mg}$ every 24 hours for 5 days with an additional $80 \mathrm{mg}$ dose 12 hours after the first dose plus Doxycycline hyclate $100 \mathrm{mg}$ ( of doxycycline ) 12 hourly for 7 days.

All the drugs were administered by oral route. The following brands were used.

Artemether - Cap Larither [Manufacture: M/s IPCA Laboratories Ltd. Mumbai]. Each capsule contained $40 \mathrm{mg}$ of artemether. Quinine was used as Tab Cinkona [Manufacture: M/s IPCA Laboratories Ltd. Mumbai]. Doxycycline was used as Cap Doxy-1 [Manufacture: M/s USV Limited, Mumbai].Each capsule containing $100 \mathrm{mg}$ of doxycycline as hyclate.

Assessment of the Efficacy of the Study Drugs: By the two variables.

a) Primary Efficacy Variables: (i) Fever Clearance Time ${ }^{14}$ : Defined as the time from the start of the treatment until the temperature measured in the mouth fall to $<99{ }^{0} \mathrm{~F}$ ( to the nearest 6 hours after start of treatment ) and subsequent sublingual temperature remained $<100{ }^{0} \mathrm{~F}$ for at least 24 hours. (ii) Parasite Clearance Time ${ }^{14}$ : Defined as the time from the start of the treatment until the first time the slide became negative ( to the nearest 12 hours after start of treatment), with subsequent blood smears remaining negative until the last study assessment on the day 28 .

b) Secondary Efficacy Variables: (i) Cure Rate: Defined as the proportion of the patients who responded to treatment and remained symptomatically relieved (i.e. no fever) as well as free from parasitemia till the $28^{\text {th }}$ day of follow up. (ii) Relapse rate: Defined as the proportion of 
the patients who responded to treatment (fever clearance and parasite clearance were achieved) but showed recurrence of symptoms (i.e. fever) and or parasitemia before the end-of-trial visit on day 28 following commencement of study medication.

Data Analysis: All the collected data were analyzed using the Statistical Package for the Social Science (SPSS) ver16 in Windows-7 and Microsoft Excel. Efficacy data evaluated by an intention-to-treat analysis for subjects who had taken study medication for at least 48 hours. Parametric data compared by the Student's t test, while non-parametric numerical data compared by the MannWhitney $\mathrm{U}$ test, with $\mathrm{p}<0.05$ was the cut-off level for statistical significance. Categorical data compared by $\chi^{2}$ test and also by the Fisher's exact test.

\section{RESULTS AND ANALYSIS}

During the May 2007 to December 2010, total 84 patients were enrolled in this study. Out of that 43 patients were allocated randomly to the $1^{\text {st }}$ group, i.e. quinine plus doxycycline group. In that group $90.697 \%$ \& $9.303 \%$ of patients were male and female respectively. Age range of that group was 15 to 60 years. All the patients were suffering from fever. Duration of fever before admission was $4.3 \pm 2.89$ (Mean \pm SD) days and highest fever before treatment was $38.7 \pm 0.69 \quad\left(\right.$ Mean \pm SD) ${ }^{0} \mathrm{C}$. In the $2^{\text {nd }}$ group 41 patients were allocated randomly i.e. they were belonged to artemether plus doxycycline group. In the $2^{\text {nd }}$ group $87.804 \% \& 12.195 \%$ of patients were male and female respectively. Average age was 23.6 7.01 (Mean \pm SD) years. All were suffering from fever. Average duration of fever was $4.5 \pm 3.59$ (Mean \pm SD) and highest temperature before treatment was $38.8 \pm 0.68$ (Mean \pm SD) ${ }^{0} \mathrm{C}$. The details of the Clinical and Laboratory characteristic of the both two groups of patients, before treatment started, are shown in the Table No. 1. \& Table No. 2.

Table No. 1: Showing the baseline Clinical Characteristics of both the two groups of the patients:

\begin{tabular}{|c|c|c|}
\hline Table No. 1 & $\begin{array}{l}1^{\text {st }} \text { Group: Quinine plus Doxycycline } \\
(n=43)\end{array}$ & $\begin{array}{l}2^{\text {nd }} \text { Group: Artemether plus } \\
\text { Doxycycline }(n=41)\end{array}$ \\
\hline Sex: $\quad$ Male & $39(90.697 \%)$ & $36(87.804 \%)$ \\
\hline Female & $4(9.303 \%)$ & $5(12.195 \%)$ \\
\hline Age: $\quad$ Mean \pm SD & $23 \pm 6.9$ years & $23.6 \pm 7.01$ years \\
\hline Range & $15-60$ years & 15-65 years \\
\hline Weight: Mean \pm SD & $49.5 \pm 5.60 \mathrm{~kg}$ & $51 \pm 5.89 \mathrm{~kg}$ \\
\hline 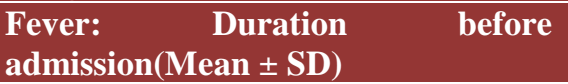 & $4.3 \pm 2.89$ days & $4.5 \pm 3.59$ days \\
\hline $\begin{array}{l}\text { Highest temperature } \\
\text { treatment }(\text { Mean } \pm \text { SD) }\end{array}$ & $38.7 \pm 0.69^{0} \mathrm{C}$ & $38.8 \pm 0.68{ }^{0} \mathrm{C}$ \\
\hline $\begin{array}{l}\text { No. of Patients } \\
\text { Splenomegaly }\end{array}$ & $14(32.558 \%)$ & $5(12.195 \%)$ \\
\hline With Hepatomegaly & $8(18.604 \%)$ & $9(21.951 \%)$ \\
\hline With First Malarial Attack & $8(18.604 \%)$ & $7(17.073 \%)$ \\
\hline Mean Parasite count & 22860 per $\mu \mathrm{L}$ & 25820 per $\mu \mathrm{L}$ \\
\hline Range of Parasite count & 412-151441 per $\mu \mathrm{L}$ & 191-185410 per $\mu \mathrm{L}$ \\
\hline
\end{tabular}

Table No.2: Showing the baseline Laboratory Characteristics of both the two groups of the patients

\begin{tabular}{|c|c|c|}
\hline $\begin{array}{l}\text { Table No.2: } \\
\text { Laboratory data }(\text { Mean } \pm \text { SD })\end{array}$ & $\begin{array}{l}1^{\text {st }} \text { Group: Quinine plus Doxycycline } \\
(n=43)\end{array}$ & $\begin{array}{l}2^{\text {nd }} \text { Group: Artemether plus } \\
\text { Doxycycline }(n=41)\end{array}$ \\
\hline Packed Cell Volume (\%) & $34.9 \pm 6.8$ & $36.3 \pm 6.2$ \\
\hline WBC Count (per $\mu \mathrm{L})$ & $4853 \pm 1419$ & $5530 \pm 4329$ \\
\hline Platelet count $\left(10^{3} / \mu \mathrm{L}\right)$ & $1661 \pm 855$ & $1593 \pm 891$ \\
\hline ESR $(\mathrm{ml} / \mathrm{hr})$ & $42.1 \pm 30.89$ & $43.6 \pm 24.53$ \\
\hline Blood Urea (mmol/L) & $6.12 \pm 2.01$ & $6.89 \pm 4.13$ \\
\hline Serum Creatinine ( $\mu \mathrm{mol} / \mathrm{L})$ & $102 \pm 10$ & $103 \pm 17$ \\
\hline Total Bilirubin( $\mu \mathrm{mol} / \mathrm{L})$ & $22.1 \pm 19.19$ & $24.13 \pm 21.3$ \\
\hline Serum AST $(\mu \mathrm{mol} / \mathrm{L})$ & $41.39 \pm 22.5$ & $51.1 \pm 22.5$ \\
\hline Serum ALT $(\mu \mathrm{mol} / \mathrm{L})$ & $39.18 \pm 22.5$ & $41.13 \pm 28.5$ \\
\hline Serum Albumin (mg/L) & $38 \pm 3.8$ & $38.5 \pm 2.9$ \\
\hline
\end{tabular}


Figure No. 1: Showing Some of the Baseline Clinical Characteristic of Both the Two Groups of Patients

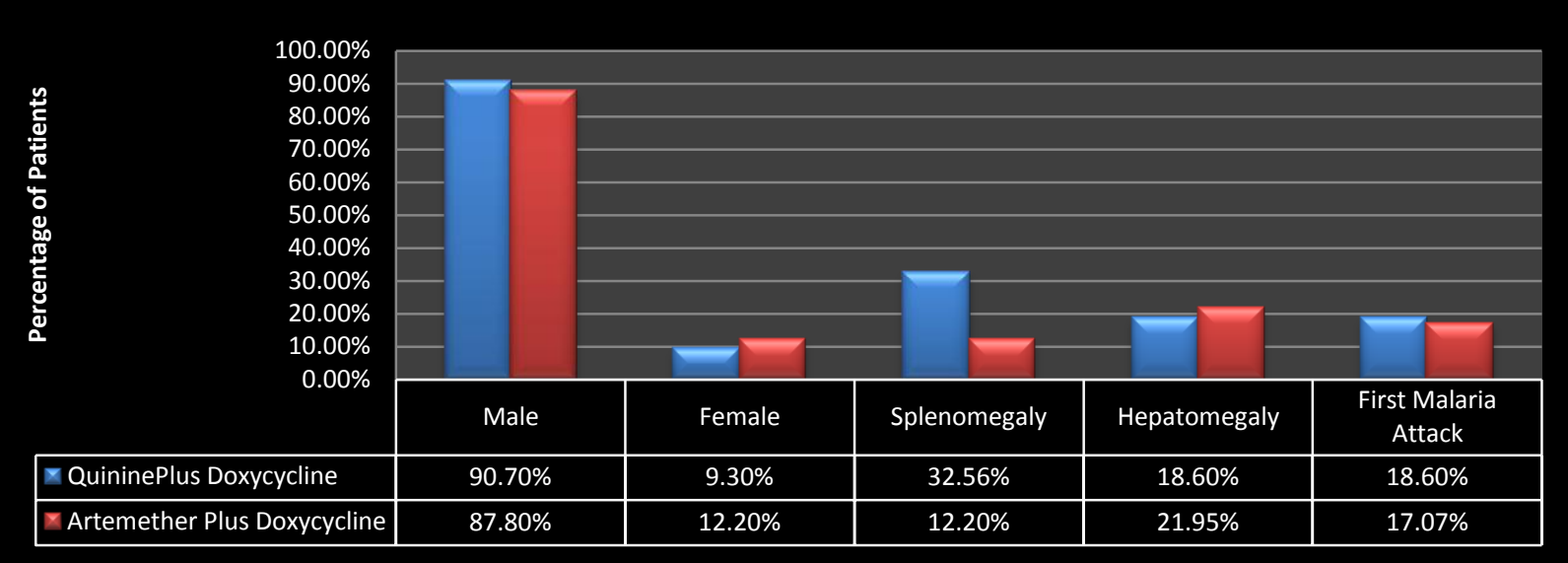

After treatment started, fever clearance time was significantly shorter in the $2^{\text {nd }}$ group (artemether plus doxycycline) than that of the $1^{\text {st }}$ group $(p=0.001)$. Similar significant faster response of parasite clearance time of the $2^{\text {nd }}$ group $(p=0.002)$. Though in the two groups, the parasite count was reduced by $80 \%$ within the 60 hours, but the mean Parasite clearance time of the $1^{\text {st }}$ group was $61.09 \pm 28.06$ hours (mean \pm SD), while that of the $2^{\text {nd }}$ group was $36.49 \pm 28.19$ hours (mean \pm SD). Fever clearance time of the $1^{\text {st }}$ group was $68.69 \pm 38.06$ hours (mean \pm SD) and that of the $2^{\text {nd }}$ group was $35.47 \pm 22.19$ hours (mean $\pm \mathrm{SD}$ ). In this study 38 patients of the $1^{\text {st }}$ group completed the last $28^{\text {th }}$ day follow-up study, while 39 patients of the $2^{\text {nd }}$ group completed the same. Cure rate of the $1^{\text {st }}$ group was $84.21 \%$, while that of the $2^{\text {nd }}$ group was $100 \%$.

The details Therapeutic Responses of both the groups are shown in the Table No. 3.

\begin{tabular}{|c|c|c|}
\hline $\begin{array}{c}\text { Table No. 3: Therapeutic Efficacy } \\
\text { Measurements: }\end{array}$ & $\begin{array}{l}1^{\text {st }} \text { Group: Quinine Plus } \\
\text { Doxycycline }(n=43)\end{array}$ & $\begin{array}{l}2^{\text {nd }} \text { Group: Artemether Plus } \\
\text { Doxycycline }(n=41)\end{array}$ \\
\hline No. of Patients with 28 days follow-up & 38 & 39 \\
\hline No. $(\%)$ Cured in 28 days & $32(84.21 \%)$ & $39(100 \%)$ \\
\hline $\begin{array}{l}\text { Fever Clearance Time (hrs) } \\
\text { Mean } \pm \text { SD }\end{array}$ & $68.69 \pm 38.06$ & $35.47 \pm 22.19$ \\
\hline Range (hrs) & 6-149 & 4-129 \\
\hline $\begin{array}{c}\text { ParasiteClearance Time(hrs) } \\
\text { Mean } \pm \text { SD }\end{array}$ & $61.09 \pm 28.06$ & $36.49 \pm 28.19$ \\
\hline Range (hrs) & 18-90 & 16-69 \\
\hline
\end{tabular}

Figure No.2: Showing the Mean Parasite Clearance Curve $(\mathrm{p}=\mathbf{0 . 0 0 2})$

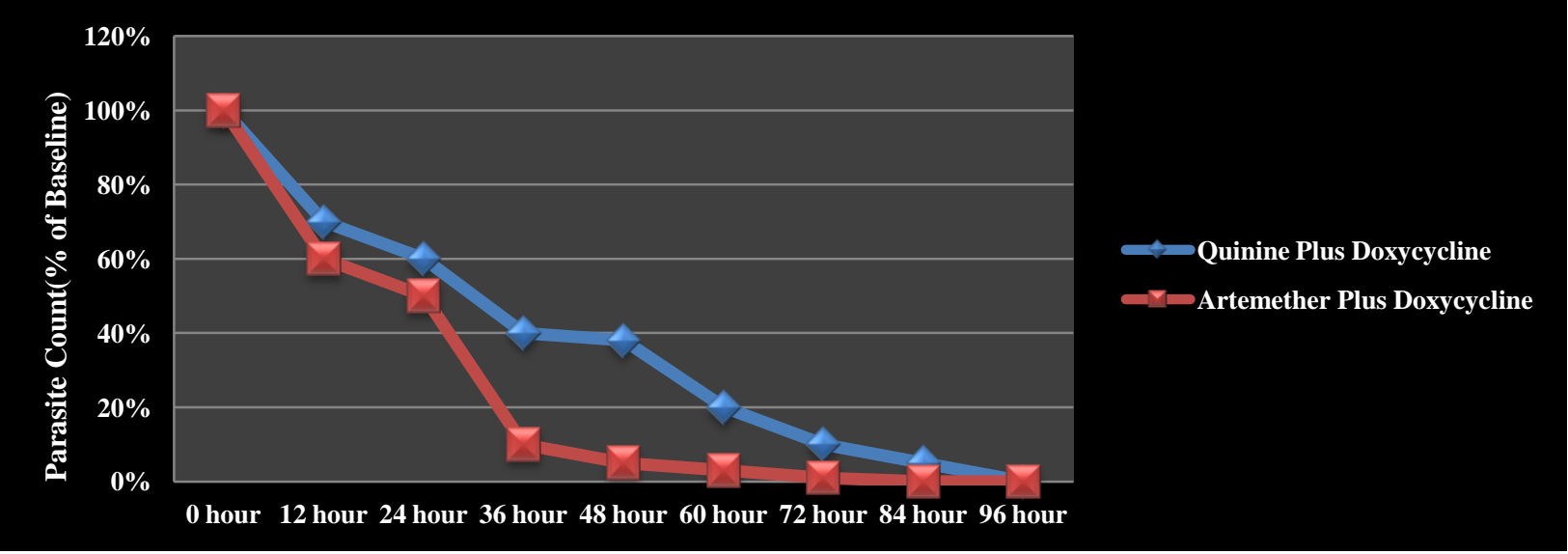

Figure 2: Time of the mean parasite clearance is distributed

The nature and the severity of the adverse drug reactions were not significantly different in both the two groups. Headache, dizziness had been noticed in only $13 \& 8$ patients of the $2^{\text {nd }}$ group, while diarrhea was most common among the $44.186 \%$ of the patients of the $1^{\text {st }}$ group. 7 artemether + doxycycline, treated patients reported nausea and 10 patients reported vomiting after 48 hours of treatment, but no additional treatment was required. No patients were discontinued from the study drug treatment due to adverse drug reaction.

Serial blood examination showed that packed cell volume gradually increased after treatment in both the groups. Absolute neutrophil counts were low before treatment in 
both groups, but gradually increased to normal values within 3-4 weeks of treatments.

The details adverse drug reaction profiles of the patients of both the two groups are shown in the Table No. 4.

\begin{tabular}{lll}
\hline $\begin{array}{l}\text { Table No. 4:Adverse Drug Reaction } \\
\text { Profile }\end{array}$ & $\begin{array}{l}1^{\text {st }} \text { Group: Quinine Plus Doxycycline } \\
(\mathrm{n}=\mathbf{4 3})\end{array}$ & $\begin{array}{l}2^{\text {nd }} \text { Group: Artemether Plus } \\
\text { Doxycycline }(\mathrm{n}=\mathbf{4 1})\end{array}$ \\
\hline $\begin{array}{l}\text { Headache } \\
\text { Abdominal Pain }\end{array}$ & $\mathbf{1 5}(\mathbf{3 4 . 8 8 \%})$ & $\mathbf{1 3}(\mathbf{3 1 . 7 0 \%}$ \\
Diarrhea & $\mathbf{1}(\mathbf{2 . 3 2 \% )}$ & $\mathbf{2}(\mathbf{4 . 8 7 5 \%})$ \\
Nausea & $\mathbf{1 9}(\mathbf{4 4 . 1 8 6 \% )}$ & $\mathbf{2}(\mathbf{4 . 8 7 5 \% )}$ \\
Vomiting & $\mathbf{6}(\mathbf{1 3 . 9 5 3 \% )}$ & $\mathbf{7}(\mathbf{1 7 . 0 7 \%})$ \\
Dizminess & $\mathbf{7}(\mathbf{1 6 . 2 7 \%})$ & $\mathbf{1 0}(\mathbf{2 4 . 3 9 \%}$ \\
\hline
\end{tabular}

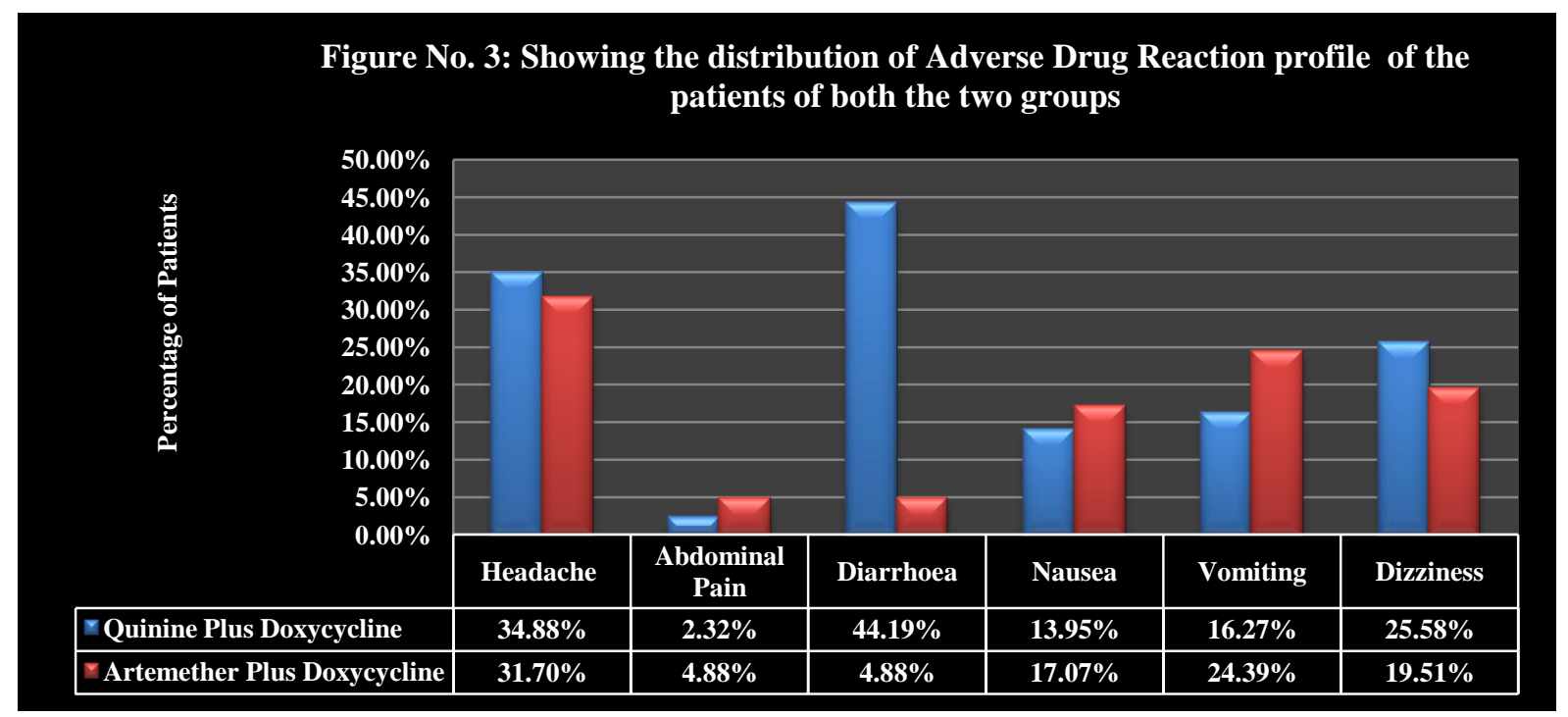

\section{DISCUSSION}

Malaria is a protozoan disease transmitted by the bite of infected Anopheles mosquitoes. The most important of the parasitic diseases of humans, it is transmitted in 108 countries containing 3 billion people and causes nearly 1 million deaths each year ${ }^{15}$. Malaria has been eliminated from the United States, Canada, Europe, and Russia; in the late twentieth and early twenty-first centuries, however, its prevalence rose in many parts of the tropics ${ }^{16}$. Malaria can behave like an epidemic disease in some areas, particularly those with unstable malaria, such as northern India (the state of Rajasthan), Sri Lanka, Iraq, and Turkey, the horn of Africa, Rwanda, Burundi, southern Africa, Madagascar, and central Asia ${ }^{17}$.

Malaria is a very common cause of fever in tropical countries. William Osler ${ }^{7}$ stated that "Humanity has but three great enemies. Fever, famine and war, of these by far the greatest, by far the terrible, is fever". The treatment of falciparum malaria has changed radically in recent years. In all endemic areas, the World Health Organization (WHO) 18 now recommends artemisinin-based combinations as first-line treatment for uncomplicated falciparum malaria. These rapidly and reliably effective drugs are sometimes unavailable in temperate countries, where treatment recommendations are limited by the registered available drugs. Fake or substandard antimalarials are commonly sold in many Asian and African countries. Thus, careful attention is required at the time of purchase and later, especially when the patient fails to respond as expected ${ }^{18}$. Current Artemisinin based combination regimens that are well tolerated in adults and children $>5 \mathrm{~kg}$ include artemether-lumefantrine, artesunate-mefloquine, artesunate-amodiaquine, artesunate-sulfoxadine-pyrimethamine, dihydroartemisinin-piperaquine \& pyronaridine ${ }^{19}$.

But when we started our study, in the early 2007, we designed to use artemether plus doxycycline combination, by following the as usual strategy of the treatment of global public health importance, likes treatment of tuberculosis, HIV/AIDS, etc.

White $\mathrm{NJ}^{20}$ stated that as a class, the artemisinins are very potent and fast-acting antimalarials, inducing more rapid parasite clearance and fever resolution than any other currently licensed antimalarial drug. They are particularly well suited for the treatment of P. falciparum malaria. . Artemisinins cause a significant reduction of the parasite burden, with a four- $\log _{10}$ reduction in the parasite population for each 48-hour cycle of intra erythrocytic invasion, replication, and regress. As such, only three to four cycles (6-8 days) of treatment are required to remove all the parasites from the blood. Additionally, artemisinins possess some gametocytocidal activity, leading to a decrease in malarial parasite transmission. Artemisinins act early in the asexual parasite development cycle, whereas 
quinine acts at the late stage ${ }^{21}$. Probably due to that reason in our study, artemether containing combination had shorter parasite clearance time \& fever clearance time and no recrudescence among the patients of the $2^{\text {nd }}$ group, it was $100 \%$ cure but in the $1^{\text {st }}$ group it was at the rate of $84.21 \%$.

In our comparative therapeutic trial of 43 months duration in total 84 patients with uncomplicated falciparum malaria, a combination of artemether plus doxycycline resulted in radical cures, with some self-limiting side effects in a few patients in comparison with quinine plus doxycycline group.

Different studies 22, 23, 24, 25 conducted in various parts of the world with the different combination of artemisinin based compound on the falciparum malaria producing varying results in their geographic area, but our study in this part of the world tally with some of the results.

\section{CONCLUSION}

Though there were limitations in this study especially involving small number of patients in only one institution, but the present study showed that artemether plus doxycycline combination was a safer and better alternative than the quinine plus doxycycline combination.

\section{REFERENCES}

[1] White NJ. The Treatment of Malaria. N Engl J Med. 1996; 335:800-6.

[2] WHO Expert Committee on Malaria. WHO technical report series No. $892.20^{\text {th }}$ report on malaria. Geneva: World Health Organization, 2000.

[3] Alnwick D. Roll back malaria- What are the prospects? Bulletin World Health Organization. 2000; 78:1377-88.

[4] Newton P and White N. Malaria: new developments in treatment and prevention. Annu Rev Med. 1999; 50: 179-92.

[5] Dorsey G, Nijama D, Kamya MR, Cattamanchi A, Kyabayinze D, Staedke SG, et.al. Sulfadoxine/pyrimethamine alone or with amodiaquine or artesunate for treatment of uncomplicated malaria: a longitudinal randomized control trial. Lancet. 2002; 360: 2031-38.

[6] Krishna S. Malaria. In: Rakel RE, Bope ET, editors. Conn's Current Therapy. Philadelphia: W.B.Saunders, 2003: p, 105-13

[7] White NJ and Breman JG. Malaria. In: Longo DL, Kasper DL, Jameson JL, Fauci AS, Hauser SL, Loscalzo J, editors. Harrison's Principles of InternalMedicine. $18^{\text {th }}$ ed.NewYork: McGrawHill; 2012, chapter 210, p, 1688-1705.

[8] Dockrell DH, Sundar S, Angus BJ, Hobson RP. Systemic Protozoal Infection. In: Colledge NR, Walker BR, Ralston SH, editors. Davidson's Principles and Practice of Medicine. $21^{\text {st }}$ ed. Edinburg; Churchill Livingstone, Elsveir, 2010; p, 348-53.

[9] Van Hensbroek MB, Onyiorah E, Jaffar S, Schneider G, Palmar A, Frenkel J, et.al. A trial of artemether or quinine in children with cerebral malaria. N Engl J Med. 1996; 335: 67-75.

[10] Bradley DJ and Warell DA. Malaria. In: Warrel DA, Cox T, Firth JD, Benz EJ, editors. Oxford Textbook of Medicine. $4^{\text {th }}$ ed. Oxford University Press. 2003; p, 721-48.

[11] Vinetz JM, Clain J, Bounkeua V, Eastman RT, Fidock D. Chemotherapy of Malaria.In: Brunton LL, Chabner BA,Knollmann BC, editors. Goodman and Gilman's The Pharmacological Basis of Therapeutics.12 $2^{\text {th }}$ ed. New York: McGrawHill; 2011, p, 1383-1418.

[12] Looarcesuwan S, Viravam C, Vanijanonta S, Wilairatana P, Suntharasamai P, Charoenlarp P, et.al. Randomized trial of artesunate amd mefloquine alone and in sequence for acute uncomplicated falciparum malaria. Lancet. 1992; 339: 821-4

[13] Good Clinical Practices. Guidelines for Clinical Trials of Pharmaceutical Products in India. New Delhi; Ministry of Health and Family Welfare, Government of India, 2001.

[14] Beadie C, Long GW, Weiss WR, McEloroy PD, Maret SM, Oloo AJ, et.al. Diagnosis of malaria by detection of Plasmodium falciparum HRP-2 antigen with a rapid dipstick antigen capture assay. Lancet. 1994; 343: 564-68.

\section{ACKNOWLEDGEMENT}

Authors are highly thankful to the laboratory technicians of the central laboratory of the Burdwan Medical College \& Hospital for providing the best facilities and good atmosphere for furnishing the different laboratory work of this study.

CONFLICT OF INTEREST AND FUNDING: The authors have no conflict of interest to declare and no funding from anywhere.

DETAILS OF THE CONTRIBUTION OF THE AUTHER: Dr Debasis Bandyopadhyay and Dr Prasanta Singha both jointly conducted the study. The first author designed and supervised the study, analyzed the results and prepared the manuscript. He will act as the guarantor of the study. The second author maintained the patient contact, administration of drugs, collected the data, follow-up visit and the most importantly, performing the laboratory test jointly with the $1^{\text {st }}$ author \& Lab. Technicians. And he helped for subsequent collection of reports from the central laboratory which remained open 24 hours in the Burdwan Medical College \& Hospital, West Bengal, India.

[15] Resolution WHA 64.17. Malaria. Sixty-fourth World Health Assembly. Geneva, 24 May 2011. http://apps.who.int/gb/ebwha/pdf files/ WHA64/A64_R17-en.pdf. [16] World malaria report 2010. Geneva, World Health Organization, 2010. http://www.who.int/malaria/world_malaria_report_2010/ .

[17] The global malaria action plan. Geneva, World Health Organization, Roll Back Malaria, 2008. http://www.rollbackmalaria.org/gmapworldmalariareport2010.pdf

[18] World Health Organization: Guidelines for the Treatment of Malaria, 2nd ed.Geneva. World Health Organization, 2010. (http://www.who.int/malaria/publications/atoz/9789241547925/en/). [19] Eastman RT, Fidock DA. Artemisinin-based combination therapies: A vital tool in efforts to eliminate malaria. Nat Rev Microbiol, 2009, 7:864-874.

[20] White NJ. Qinghaosu (artemisinin): The price of success. Science, 2008, 320:330-334.

[21] Dondorp A et al: Artesunate versus quinine in the treatment of severe falciparum malaria in African children (AQUAMAT): An open-label randomized trial. Lancet.2010; 376:1647.

[22] McGready R, Tan SO, Ashley EA, et al. A randomised controlled trial of artemether-lumefantrine versus artesunate for uncomplicated plasmodium falciparum treatment in pregnancy. PLoS Med, 2008, 5:e253.

[23] Sinclair D, Zani B, Donegan S, et al. Artemisinin-based combination therapy for treating uncomplicated malaria. Cochrane Database Syst Rev, 2009, CD007483.

[24] Davis TM, Karunajeewa HA, Ilett KF. Artemisinin-based combination therapies for uncomplicated malaria. Med J Aust, 2005, 182:181-185.

[25] German PI, Aweeka FT. Clinical pharmacology of artemisininbased combination therapies. Clin Pharmacokinet, 2008, 47:91-102. 